On manipulation the swelling can be entirely reduced within the chest by gently pressing upon the fundus and fixing the blunt neck at the first intercostal space. The swelling vanishes with a squeaking sound quite audible both to the patient and to the operator. The sitting posture and a few coughs bring the hernia again into prominence.

The photographs here reproduced were kindly taken for me by Dr. W. B. Anderton. The one shows the hernia before and the other after reduction.

My best thanks are due to Dr. Edge for kindly allowing me to record the case.

Bristol.

\section{OPEN SAFETY PIN IN THE CESOPHAGUS OF A CHILD AGED FIVE MONTHS.}

BY J. S. Manson, M.B., CH.B. Edin., SENIOR HOUSE SURGEON, OLDHAM INFIRMARY.

A MALE child, aged five months, was admitted to the Oldham Infirmary on Oct. 26th, 1906, with history of having swallowed a safety pin one hour previous to admission. A skiagram was taken and the pin was seen to lie about the middle of the cesophagus, open with the point upwards. It seemed a hopeless task to try to get the pin up by means of a probang, so it was resolved to push the pin down into the stomach and hope for the best. An ordinary stomach tube of small size was pushed down the œsophagus, and after withdrawing another skiagram was taken showing the pin lying in the stomach. The child was kept in bed and watched carefully. Milk diet was given and four days after admission

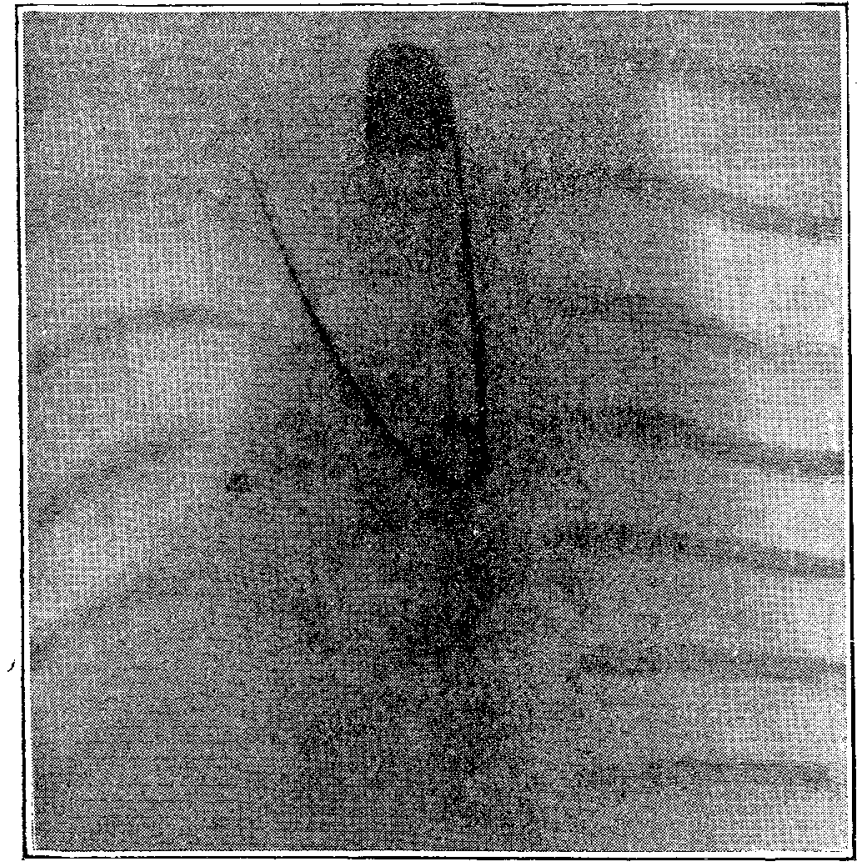

a dose of castor-oil. On the afternoon of Nov. 2nd the pin was found sticking half-way out at the anus. The pin took six and a quarter days to accomplish the journey from the mouth to the anus and only once or twice did the child seem at all fretful.

The case seems northy of not: in showing the power of the alimentary canal in dea in 5 with a toreign body of a somewhat formidable rature. I append a skiagram of the pin in the cesophagus.

\section{A CASE OF "MIRROR-WRITING."}

By Vaughan Penured, M.D. Durh, F.R.C.S. Eng.

A CURIous condition that justly has been called " mirrorwriting" has recently come under my observation. A bright, intelligent little lad, aged six rears, has been learning to write for the past six months. His governess reports favourably of his application and progress, and no abnormality save the one here reported has been noted. From a copy the boy writes correctly but if left to himself to exercise his new-found accomplishment, of which he is very proud, he starts at the right hand side of the paper and writes backwards, so that to decipher the writing the paper has to be held up to a mirror. One day his mother suggested that he should write a letter to his grandmother. He began the letter as shown in Fig. 1 (the $G$ is correctly formed as he copied from a letter in his mother's handwriting). He selects the "mirror-writing" when asked

FIG. 1 .

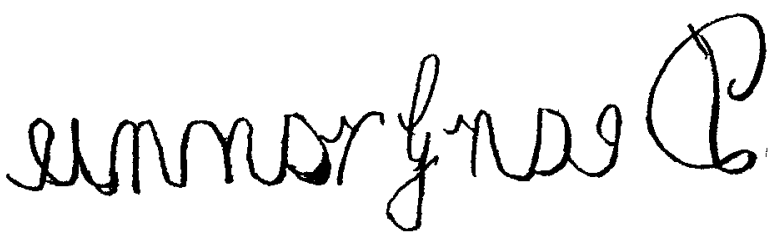

which is correct. He reads with equal facility both the normal and the abnormal types. For example, his mother indited in " mirror-writing" the invitation contained in the three first lines of Fig. 2, to which he instantly wrote, currente calamo, the reply contained in the remaining lines of the same illustration. The most extraordinary confusion arises when he attempts "sums," as shown in Fig. 3. A drawing that he made of a Great Northern locomotive engine illustrates the defect in a very marked way. The

FIG. 2.
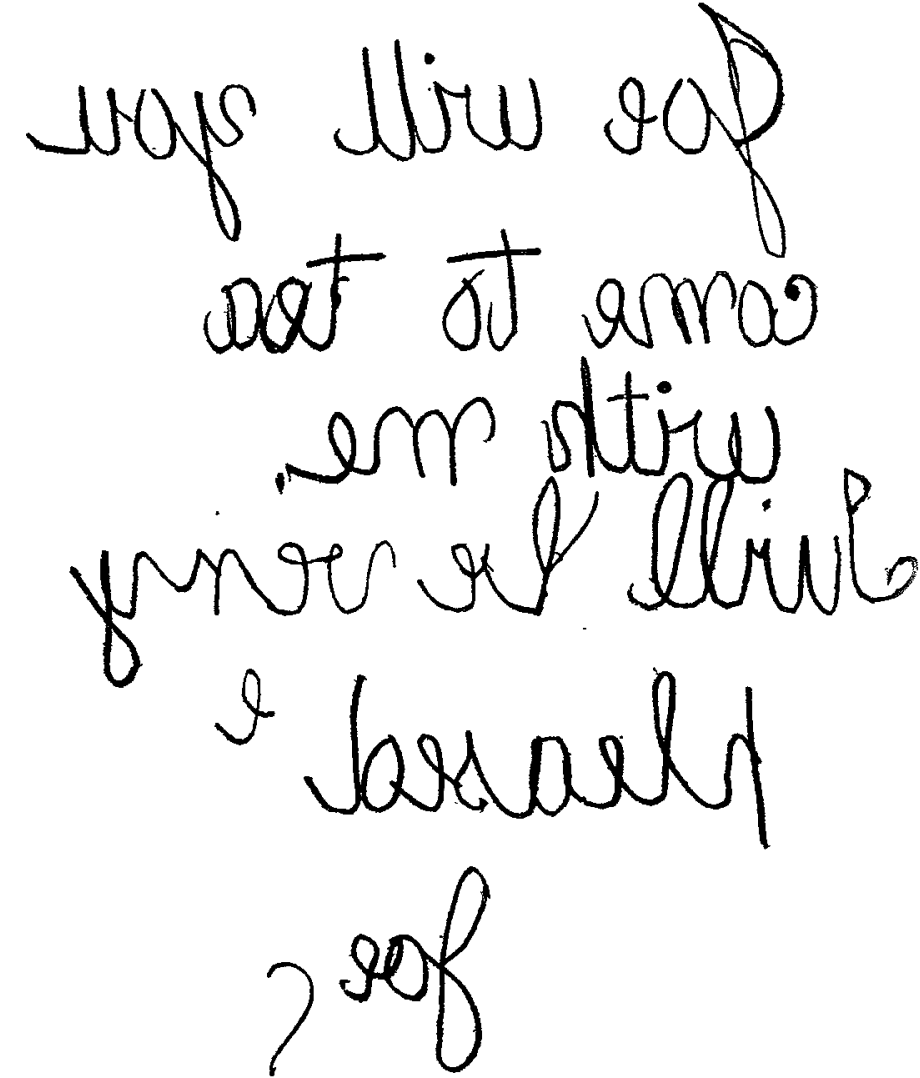

engine is shown travelling to the left and is very well drawn for so youthful an artist; the letters G.N.R. on the tender are in " mirror-writing." In writing from dictation, unless he is corrected and carefully watched, he reverses his work.

Are the pictures of letters in the boy's memory-centre incorrectly stored and therefore incorrectly reproduced? Does the receptive apparatus in the occipital lobes play this strange prank with the naturally inverted picture of letters

FIG. 3.

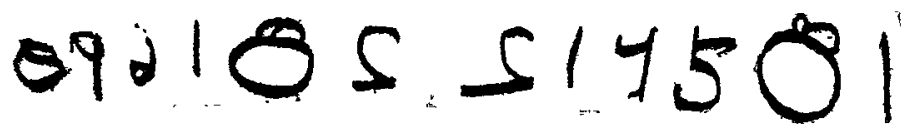

received on the boy's retinæ? It must be noted that the letters are not inverted as would be the case if the brain merely failed to right the retinal images. I incline to the former hypothesis as it is only in the reproduction of written words that he fails and is quite secure in making a copy. Coventry. 